\title{
A functioning black adenoma of the adrenal cortex: A clinico-pathological entity
}

\author{
J. W. VISSER, J. K. BOEIJINGA, AND C. v.D. MEER
}

From the Pathologisch Instituut and Department of Internal Medicine, Vrije Universiteit, Amsterdam, The Netherlands

SYNOPSIS A 25-year-old woman is described who had suspected hyperfunction of the adrenal cortex. She complained of fatiguability, excessive hair growth, and attacks of swelling of the face, hands, and ankles. Moreover she had a 'moon face', hypertension, a 'buffalo hump', and livid striae of the loins and hypogastrium. Adrenal function tests yielded values which could not be clearly interpreted.

Operation showed a 'black adenoma' of the adrenal cortex on the right side. As far as it is known this is the first published case of this extremely rare lesion which was operated upon and caused nearly complete remission of the endocrine disturbance.

\section{Case Report}

A 25-year-old woman was admitted to hospital on 29 September 1971. The symptoms were extreme fatiguability and the development of excessive hair on chin, upper lip, legs, and back in the course of four to six months.

She suffered once or twice a week from attacks of swelling of the face, hands, and occasionally the ankles, lasting from about 15 minutes to several hours. She also complained of pain, diffusely located in the abdomen and loins, predominantly on the right side, starting in March 1971. The character of the pain was pressing and the attacks lasted about one hour, with a frequency of three to four times a week.

From her 14th year she had had epilepsy and throughout her stay in hospital she received $50 \mathrm{mg}$ diphantoin tid. In the latter half of 1969 the interval between the intermenstrual periods had become irregular, varying from four to seven weeks, the duration of the menstrual periods and the extent of bleeding remaining normal.

The patient was seen in 1970 by a houseman for the evaluation of adrenocortical function, because of the possibility of hypercorticism. Endocrinochemical screening gave normal values for 17-hydroxycorticoids, total 17-ketosteroids, and cortisol (including circadian rhythm).

Stimulation or suppression tests were not performed. The diagnosis was polycystic ovaries.
At laparotomy the ovaries showed a granular surface, locally the omentum had a dull aspect, and a bilateral wedge biopsy was performed.

Pathologically an increase of fibrocollagenous tissue was seen, for which no obvious cause could be found. The pathological diagnosis was the SteinLeventhal syndrome, ie, polycystic ovaries. On inspection her face appeared somewhat swollen, rounded, and flushed, a 'moon face', and excessive 'lugano type' hair growth was present over the body. The ankles on both sides showed minimal oedema. The blood pressure was $170 / 115 \mathrm{mmHg}$. The size of the clitoris was normal.

During the first weeks of clinical observation, a definite 'buffalo hump' and livid striae, on the hypogastrium and laterally on the flanks, developed relatively rapidly. Her chief complaints were of spells of abdominal pain, general malaise, and a feeling of a swollen abdomen and head.

Urinalysis, haematology, blood clotting tests, routine blood chemistry (including $\mathrm{Na}, \mathrm{K}$, urea, creatinine, $\mathrm{Ca}, \mathrm{P}$, cholesterol, uric acid, liver functions, protein spectrum), glucose tolerance and coagulation tests, all showed normal values.

Routine $x$-ray examination of the thorax, abdomen, and sella, and oral cholecystography and intravenous pyelography yielded no abnormalities. On planigraphy of the adrenals an enlarged adrenal was seen on the right side.

\section{Results}

On stimulation and suppression of the adrenal 
cortex, values were obtained which could not be clearly interpreted; only with $16 \mathrm{mg}$ of dexamethasone was there a definite suppression. The metopiron (Metyrapone) test performed twice showed no reaction. Further normal endocrino-chemical values were found for aldosterone, moma, and ACTH.

On the basis of the symptoms, planigraphy, and laboratory findings the existence of either an autonomous adenoma or carcinoma of the right adrenal cortex seemed probable. A right-sided explorative lumbotomy was performed together with adrenalectomy. After the operation urinary 17-OHCS, 17-KS, and serum cortisol showed very low values. Supplementary therapy was given.

Clearly the patient's left adrenal had undergone a certain degree of atrophy caused by longstanding hyperfunction of the right adrenal.

During the follow-up period as an outpatient, three months after discharge the blood pressure had become normal, the moon face and 'buffalo hump' had completely disappeared, and the livid striae gradually faded. After six months the excessive hair growth had also disappeared. Six months later neither subjective nor objective signs of adrenal dysfunction remained. The medication was reduced to $5 \mathrm{mg}$ cortisone acetate every other day. One year after operation normal 17-OHCS, 17-KS, and cortisol values were found. ${ }^{1}$

\section{PATHOLOGICAL METHODS}

The operation specimen was received immediately from the operating theatre. Complete transverse sections were made through the specimen in the longitudinal axis. Representative sections were

Detailed laboratory results (values, methods, etc) are available on request.

fixed in buffered $10 \%$ formaldehyde and embedded $\stackrel{0}{\overrightarrow{0}}$ in paraffin. The paraffin-embedded material was sectioned at $6 \mu$ and treated and stained, as shown $\underset{\vec{F}}{\vec{p}}$ in the table.

DESCRIPTION OF THE ADRENALECTOMY SPECIMEN

\section{Macroscopy}

The specimen was a right adrenal measuring $5 \times 3 \vec{\circ}$ by maximum $2.3 \mathrm{~cm}$, weighing 9 grams. A well circumscribed nodule of 3.5 by 2.5 by $2 \mathrm{~cm}$ was $\vec{\omega}$ seen, smooth, and showing a black transparency beneath the surface and slightly bulging (fig 1). On multiple sections the node showed a brownish black i even surface and was completely surrounded by adrenal tissue. Adjacent to the node a normal adrenal structure seemed to be present.

\section{Microscopy}

The tumour is seen to be composed of groups of $\vec{\nabla}$ four to eight cells of epithelial configuration and $\stackrel{\mathbb{\perp}}{\varnothing}$ character. These cells show no definite borders and $\stackrel{\oplus}{3}$ the groups are divided by fine septa and sinusoidlike cavities, resembling the reticular zone of the adrenal cortex (fig 2).

The most striking phenomenon is the extreme pigmentation of the cytoplasm of most of the cells. this is of a varying dark brown to golden browi colour in the haematoxylin-eosin stain. It is sometimes delicately granular and sometimes coarser. Occasionally a mitosis is seen (fig 3). The pigment of the tumour cells remains unstained by the van Gieson, Schmorl, Gomori's chromaffine, iron, mucicarmine staining methods. Varying amounts of staining were seen in the Fontana, Congo red,

\begin{tabular}{|c|c|c|c|}
\hline & Present Case & $\begin{array}{l}\text { Reticular Zone of Normal } \\
\text { Adrenal }\end{array}$ & Staining Colour of Granules \\
\hline $\begin{array}{l}\text { Weight } \\
\text { Endocrine activity } \\
\text { Autofluorescence } \\
\text { Sudan black on paraffin embedded tissue } \\
\text { H and E } \\
\text { van Gieson } \\
\text { Periodic acid Schiff ( } \pm \text { diastase) } \\
\text { Mallory } \\
\text { Fontana } \\
\text { Bodian } \\
\text { Schmorl } \\
\text { Giemsa } \\
\text { Gomori's chrome } \\
\text { Gomori's silver } \\
\text { Iron (Perls') } \\
\text { Congo red } \\
\text { Crystal violet } \\
\text { Mucicarmine } \\
\text { Acid fast } \\
\text { Luxol fast blue }\end{array}$ & $\begin{array}{l}9 \mathbf{g} \\
++ \text { Cushing's syndrome } \\
++ \\
\pm \\
-- \\
-- \\
+ \\
+ \\
\pm \text { (variable) } \\
+ \\
\overline{+}- \\
\overline{+}- \\
+ \\
\pm- \\
\pm \\
\overline{ \pm}- \\
\pm \\
+\end{array}$ & $\begin{array}{l}--- \\
+ \\
+ \\
\pm \\
-- \\
-- \\
+ \\
+ \\
\pm \text { (variable) } \\
+ \\
+- \\
+- \\
+ \\
-- \\
-- \\
-- \\
-- \\
+\end{array}$ & $\begin{array}{l}\text { Yellow fluorescence } \\
\text { Black } \\
\text { Golden brown } \\
\text { Golden brown } \\
\text { Bright red } \\
\text { Reddish purple } \\
\text { Brownish black } \\
\text { Black outer rim } \\
\text { Golden brown } \\
\text { Bluish green } \\
\text { Golden brown } \\
\text { Black outer rim } \\
\text { Golden brown } \\
\text { Golden brown } \\
\text { Light purple } \\
\text { Golden brown } \\
\text { Bluish green } \\
\text { Purple }\end{array}$ \\
\hline
\end{tabular}

Table Summary of laboratory results 

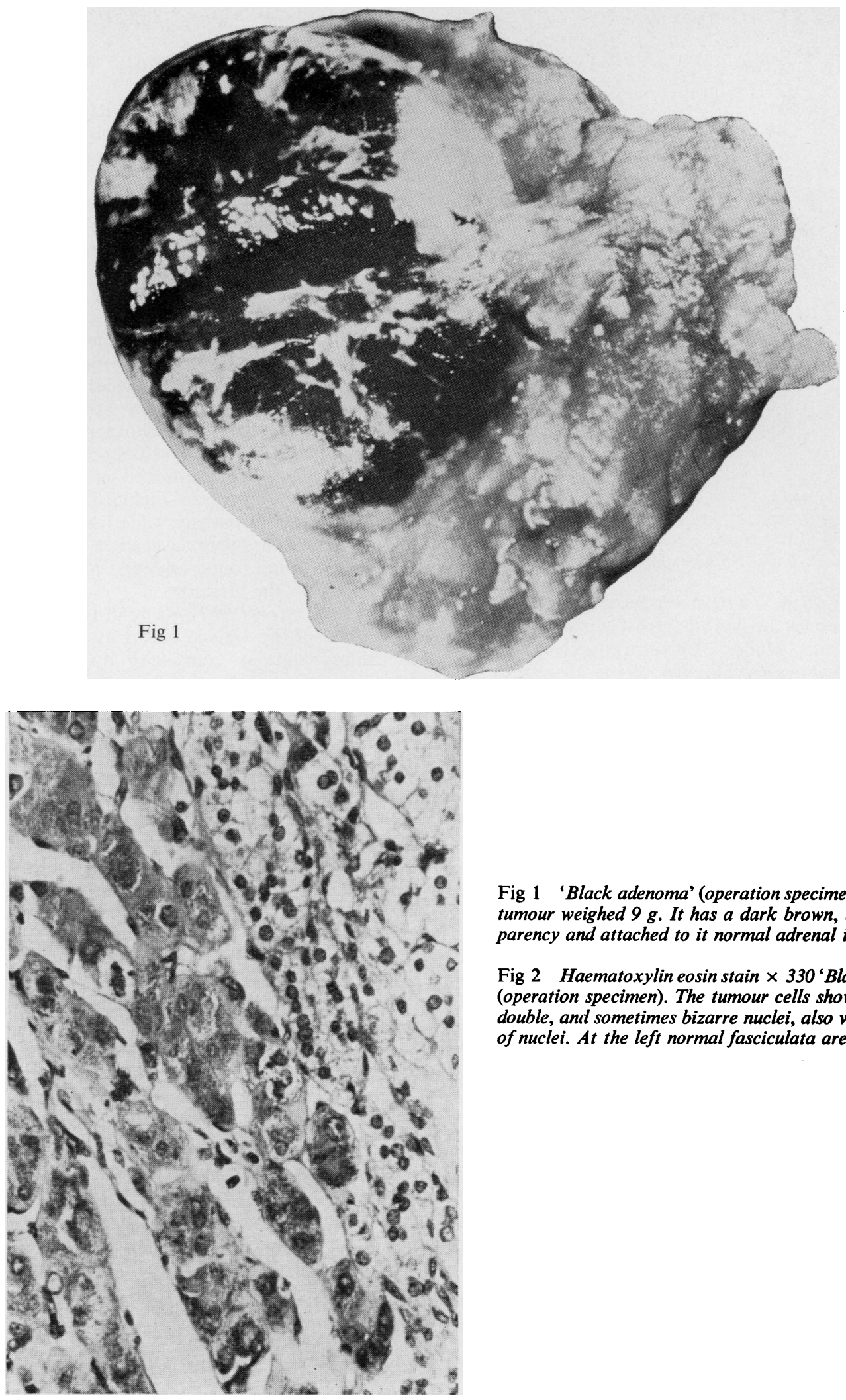

Fig 1 'Black adenoma' (operation specimen) $\times 1 \cdot 2$. The tumour weighed $9 \mathrm{~g}$. It has a dark brown, blackish transparency and attached to it normal adrenal is seen.

Fig 2 Haematoxylin eosin stain $\times 330$ 'Black adenoma' (operation specimen). The tumour cells show pleomorphic, double, and sometimes bizarre nuclei, also vacuolization of nuclei. At the left normal fasciculata are seen.

Fig 2 


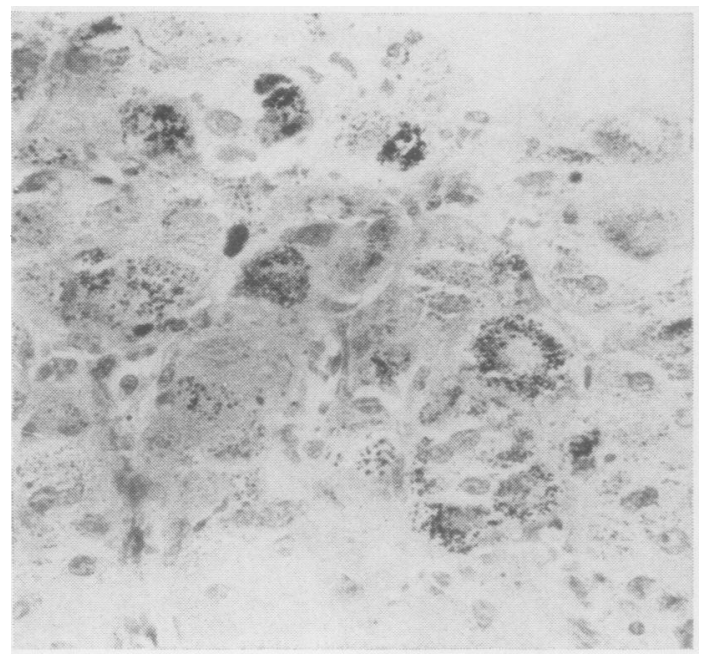

Fig 3 Fontana stain $\times 330$ (operation specimen). The tumour cousists of groups of cells which show coarse and sometimes finer granules in the cytoplasm, staining dark brown to black in the Fontana stain.

crystal violet, and acid fast staining methods. Definite staining was seen by the periodic acid-Schiff (before and after diastase), Mallory, Giemsa, and luxol fast blue staining techniques. Staining of the outer rim of the granules was observed by the Gomori's silver and Bodian techniques. When the same staining methods were performed on a normal adrenal gland of a 32-year-old patient who died after an accident, the zona reticularis of this gland was stained in exactly the same way as the 'black adenoma' (see table).

The tumour cells are polyhedral and larger than those of the zona reticularis which they strongly resemble. They possess an eosinophilic cytoplasm, the nuclei are round to oval, larger than those of the reticular zone, and have distinct nucleoli. The nuclei are strongly pleomorphic and in the periphery bordering on the preexistent zona fasciculata double nuclei, bizarre large nuclei, and sometimes nuclear vacuolization are seen (fig 2). The tumour reaches the surface in some areas and sometimes is only coated by a fibrous capsule. In other places only remnants of the zona fasciculata are recognizable. In one place a strip of preexistent zona reticularis with sinusoids is seen. Medullary tissue could not be found in the tumour but only in the adherent adrenal tissue. Compared with an adrenal of a normal adult of this age, the thickness was 15 to $20 \%$ thinner; the capsule also was thickened.

\section{Discussion}

Non-functioning pigmented nodules (pigmented nodular or adenomatous hyperplasia) have been extensively described in the past (Baker, 1938; Lüders, 1953; Macadam, 1971). These can be differentiated as (a) lipofuscin-containing nodes, (b) melanin-containing nodes, (c) primary melanoma, (d) secondary melanoma, (e) haemangioma, and ( $f)$ myelolipoma of the adrenal.

Several of these lesions have been described in the past as 'black adenomas', 'pigmented adenomas', or 'pigmented nodes or nodules' of the adrenal (cortex).

Lipofuscin-containing nodes have been found in 37 of 100 consecutive routine necropsies by Robinson, Pardo, and Rywlin (1972). Furthermore they could not find any correlation with age nor were there endocrinological disturbances in these cases. Symington (1969) is the only author who correlates a Cushing's syndrome with a pigmented or black adenoma, ie, a lipofuscin-containing adenoma. Three cases are mentioned in his book and electron micrographs are included showing definite differences from patients suffering from an adenomatous or nodular hyperplasia and a Cushing's syndrome. We have not found any reports concerning these patients in the literature.

Following Symington (1969), we wish to define a 'black adenoma' of the adrenal cortex as an encape sulated, solitary tumour containing no or littio f fibrocollagenous tissue but consisting of trabecula of cells, derived from and resembling those of the zona reticularis, only larger. Black adenomas contain pigment granules, which are characteristic for the lesion, but which can be found in the normal zona reticularis of the adrenal cortex. They cause atrophy of the remainder of the adjacent cortex, as well as of the contralateral adrenal cortex, when hormonally active, and they show definite pleomorphism of the nuclei of the tumour cells, being exclusively onesided and solitary.

Concluding, we wish to postulate that the term 'black adenoma' should be restricted to real adenomas, originating as a neoplasm from the reticular zone of the adrenal cortex; it is an extremely rare lesion. This lesion is capable of causing endocrine disturbances (in this case presenting as Cushing's syndrome) in the patient in contradiction to earlier published cases.

The endocrine disturbances disappear completely after removal of the adenoma, but supplementary therapy is always necessary postoperatively.

The pigment found in the lesion is typical and responsible for the macroscopic appearances but can be found in the normal reticular zone.

The strong pleomorphism of the nuclei suggests malignancy, but is in contradiction to the benign nature of the lesion. 
We acknowledge the valuable consultation of Professor R. Donner, Head of the Department of Pathology of the Vrije Universiteit, the valuable criticisms of Dr J. D. Wiener, the endocrinological bioassays of Mrs A. C. Akkerman-Faber and Mrs C. Popp-Snijders, the technical assistance of Mr G. J. Oskam and $\mathrm{Mr} \mathrm{T}$. Lobbes, and the secretarial assistance of Mrs H. C. Visser-Wortel.
References

Baker, M. R. (1938). A pigmented adenoma of the adrenal. Arch. Path., 26, 845-852.

Lüders, C. J. (1953). Zur Frage der pigmentierten Nebennierenrindenadenome. Virchows Arch., path. Anat., 324, 123-135.

Macadam, R. F. (1971). Black adenoma of the human adrenal cortex. Cancer (Philad.), 27, 116-119.

Robinson, M. J., Pardo, V., and Rywlin, A. M. (1972). Pigmented, nodules (black adenomas) of the adrenal. Hum. Path., 3, 317-325.

Symington, T. (1969). Functional Pathology of the Human Adrenal Gland. Livingstone, Edinburgh, Williams and Wilkins, Baltimore. 